\title{
GIOVANNI BATTISTA SESTI Y EL “ATLAS DEL ESTADO DE MILÁN” IDEADO PARA EL PRÍNCIPE EUGENIO DE SABOYA: DE MILÁN A MADRID*
}

\author{
VALERIA MANFrÈ ${ }^{1}$ \\ Universidad de Valladolid
}

\begin{abstract}
El análisis de un atlas manuscrito del Estado de Milán, conservado en la Biblioteca del Palacio Real de Madrid, permite analizar su contenido en relación a su versión impresa en 1707. El estudio de ambas versiones, dedicadas al príncipe Eugenio de Saboya (1663-1736), así como el análisis de los catálogos de la biblioteca del príncipe, han permitido determinar sus intereses coleccionistas, incluso en obras cartográficas relacionadas con la península ibérica. El artículo ahonda también en la trayectoria profesional de su artífice, el ingeniero milanés Giovanni Battista Sesti (1633 - ca. 1725) al servicio de la corona española.
\end{abstract}

Palabras clave: Giovanni Battista Sesti; Milán; Atlas; Eugenio de Saboya; José Chafrion; Dibujo; Coleccionismo; Cartografía militar.

\section{GIOVANNI BATTISTA SESTI AND THE “ATLAS OF THE STATE OF MILAN” DEVISED FOR PRINCE EUGENE OF SAVOYA: FROM MILAN TO MADRID}

The analysis of a manuscript atlas of the State of Milan at the Biblioteca del Palacio Real of Madrid, allows to analyze its content in relation to its printed version in 1707. The study of both versions, dedicated to Prince Eugene of Savoy (1663-1736), as well as the analysis of the catalogs of the prince's library, have allowed to determine his collector interests, even in cartographic collections related to the Iberian Peninsula. The article also analyses the professional trajectory of its author, the Milan engineer Giovanni Battista Sesti (1633 - ca. 1725), in the service of the Spanish crown.

Key words: Giovanni Battista Sesti; Milan; Atlas; Eugene of Savoy; José Chafrion, Drawing; Collecting; Military cartography.

Cómo citar este artículo / Citation: Manfrè, Valeria (2020): “Giovanni Battista Sesti y el 'Atlas del Estado de Milán’ ideado para el príncipe Eugenio de Saboya: de Milán a Madrid”. En: Archivo Español de Arte, vol. 93, núm. 370, Madrid, pp. 113-130. https://doi.org/10.3989/aearte.2020.08.

El objeto de esta investigación es el ingeniero milanés Giovanni Battista Sesti (1633-ca.1725), técnico involucrado en la definición y valoración de las fortificaciones de algunas áreas de la península italiana sometidas al dominio de la monarquía hispánica, autor de un atlas del ducado de Milán, y el príncipe Eugenio de Saboya, gran mecenas y coleccionista, así como destinatario del atlas. En la primera parte de este estudio se analizará la carrera profesional de Sesti siguien-

\footnotetext{
* Este trabajo se ha realizado gracias a la financiación del Ministerio de Economía y Competitividad de España (Programa Juan de la Cierva-incorporación) en el marco del proyecto de investigación I+D del MINECO HAR201679442-P Hacia Antonio Acisclo Palomino. Teoría e historiografía artísticas del Siglo de Oro.

1 valeriamanfre@gmail.com / ORCID iD: http://orcid.org/0000-0002-7804-7568
} 
do la estela de un artículo precedente, escrito por mí misma, en donde se revisaron y aportaron datos sobre Giovanni Battista y su padre, desconocido en el marco de los estudios científicos, que estuvo al servicio de la Corona, es decir el ingeniero Giovan Paolo (1591-1647) ${ }^{2}$. En aquel trabajo fue indispensable cruzar documentos de archivos, hasta entonces obviados, que permitieron dar a conocer dibujos y fuentes inéditas y revisar algunos datos biográficos, entre otros, la fecha de nacimiento de Giovanni Battista que, respecto a los estudios precedentes, hemos anticipado al año 1633. Todo ello aun cuando sigue siendo difícil precisar con exactitud las fechas de estancia del ingeniero Sesti en cada lugar en donde trabajó, pero es posible realizar una aproximación sobre este aspecto a través de una fuente prácticamente única y en parte inédita: los dibujos hológrafos ubicados en diferentes bibliotecas y archivos de España e Italia y la información documental de su etapa siciliana localizada en el Archivo General de Simancas, que concierne los proyectos para nuevas obras defensivas.

Más adelante se examina la producción gráfica realizada por el ingeniero militar Giovanni Battista, a través del análisis de un atlas de la Biblioteca del Palacio Real de Madrid, un manuscrito que representa el ducado de Milán, realizado en 1707, y dedicado al príncipe Eugenio de Saboya, coleccionista y bibliófilo, cuyas inclinaciones culturales se revelan mediante los Catalogus de su librería que hoy se conservan en los fondos de la Österreichische Nationalbibliothek de Viena. El análisis del material recopilado por parte de Sesti permite extrapolar, en parte, el proceso creativo y estético al que fue sometido el dibujo técnico recopilado en el atlas de Madrid y destinado a la imprenta.

\section{El dibujante ingeniero}

El déficit historiográfico que acomunan la mayoría de los ingenieros que trabajaron al servicio de la monarquía hispánica incluye también al protagonista de las siguientes páginas ${ }^{3}$. Sobre Giovanni Battista Sesti ${ }^{4}$, por lo general, falta un estudio detallado de su trayectoria profesional, así como un análisis pormenorizado de la producción cartográfica de carácter militar identificada hasta la fecha. A partir de este corpus trataremos de analizar el recorrido de los dibujos de Sesti que aportan una doble vertiente informativa: por un lado, su contenido, por otro, el itinerario de los viajes que realizó durante su vida. Sesti fue un profesional capaz de utilizar el diseño técnico con gran destreza constituyendo así la principal herramienta de su profesión. Las referencias proporcionadas por la documentación original sobre el artista se refieren a los siguientes diseños: la ciudad de Lodi, fechada en el año 1665, con la representación de sus baluartes ${ }^{5}$, los proyectos de fortificación realizados en Sicilia para las ciudades de Messina, Siracusa y Milazzo y la planta del castillo de Milán ideada durante el sitio de $1707^{6}$. Este último tiene particular interés, porque se reutilizó, como veremos más adelante, tal y como su propia realización además refleja, el proceso de recepción e interpretación del mismo, y la extensión de su utilización permite contextualizarlo en un discurso más amplio de índole decorativo y de celebración.

A este respecto, los estudios sobre el reducido corpus de dibujos de Sesti se refieren, sobre todo, al periodo siciliano. En la isla, las responsabilidades de Sesti fueron significativas dado que aquí residió casi diez años, entre 1674 y 1683, y se relacionó con otros personajes de su misma profesión. En Sicilia puso de manifiesto su dominio del dibujo a través de dos diseños ideados durante el gobierno del virrey Vincenzo Gonzaga en el año 1678, cuando la turbulenta situación

\footnotetext{
2 Manfrè, 2017.

3 Vesco, 2015

${ }^{4}$ Para los datos biográficos véase Roncai / Viganò, 2007: 130 y las nuevas aportaciones dada a conocer por Manfrè, 2017.

5 Archivio di Stato, Milano (ASMi) Militare, p.a. 333, 1665, tinta de colores a la aguada, 292 x $431 \mathrm{~mm}$.

${ }^{6}$ Biblioteca Trivulziana, Milano (BTMi), Belgioioso, cartella 262, doc. 222, 1707, dibujo a pluma y acuarela, 516 x $589 \mathrm{~mm}$.
} 
después de la revuelta antiespañola de la ciudad de Messina (1674-1678), reclamaba un buen sistema de defensa ${ }^{7}$. Ambos, fechados el 6 de mayo de 1678, aluden al aparato defensivo de la ciudad de Messina que se reforzó a partir de la construcción de una ciudadela que debía ocupar una parte del denominado como Piano di Terranova ${ }^{8}$. Los dibujos de Sesti se acompañaron de un informe muy detallado, fechado el 4 de mayo de $1678^{9}$, aunque finalmente la propuesta del ingeniero milanés fue descartada a favor del proyecto de la ciudadela pentagonal, mucho más complejo y dispendioso, del ingeniero alemán Carlos de Grunenbergh $(† 1696)^{10}$. Este especialista fue auxiliado por un ayudante y, aunque se había descartado el proyecto de Sesti para la ciudadela de Messina, durante la ausencia de Grunenbergh de la ciudad del Estrecho las obras se confiaron al ingeniero Sesti ${ }^{11}$.

Un testimonio ulterior también conocido es el dibujo de la ciudad de Siracusa [fig. 1], enviado desde Palermo a Madrid por el virrey Francisco de Benavides Dávila y Corella, IX conde de Santisteban del Puerto (1678-1687), el 5 de mayo de 167912. El ingeniero Sesti, según las aclaraciones descritas en la leyenda, incide en la importancia de la utilización del color en los documentos cartográficos. A partir de los planos del siglo XVI, el color se convirtió en el protagonista del dibujo técnico, una fórmula explicativa utilizada por los ingenieros en sus propios planos y proyectos ${ }^{13}$; el rojo fue utilizado para representar las obras ya realizadas, el amarillo se incorporó para enfatizar aquello que todavía quedaba pendiente. Lo que se había realizado en Siracusa era la obra coronada, con falsabraga y camino cubierto, las obras en los baluartes de San Felipe y Santa Lucía con los cuarteles para la infantería y caballería, así como la plataforma y la falsabraga del castillo Maniace en la punta de Ortigia. De la documentación se desprende que "en las fortificaciones de la parte de tierra es menester terraplenar una cortina nueva que mira al puerto, perfeccionar el terraplén de la obra encoronada, el del revellín del puerto y del parapeto de la falsabraga al pie del baluartes de santa Lucia, hacer las quatro puertas y puentes levadizos, y reparar otras que ya están maltratadas”14.

En cuanto al dibujo de Milazzo de la Biblioteca Trivulziana [fig. 2], se ha hipotizado una fecha de ejecución entorno al año $1675^{15}$. Durante la década de 1670 , el programa de defensa urbana de la costa oriental de Sicilia tuvo cabida bajo el gobierno del virrey Gonzaga (1678). En uno de los informes enviado a Madrid, fechado en octubre de $1678^{16}$, el virrey informaba del interés que había prestado para guarnecer de nuevas obras defensivas las ciudades de Augusta, Siracusa y la aldea de Milazzo y concluía, en este sentido, señalando que "se han añadido las fortificaciones de Melazo y Zaragoza. Que a la primera le falta muchisimo para acabarla y la segunda algo"17. Así mismo, reconocía que, por falta de medios, no había logrado hacer mucho más y por ello, recomendaba que se hiciese cargo su sucesor ${ }^{18}$, es decir, el virrey Santisteban,

7 Sobre las causas, el desarrollo y las consecuencias de la revuelta de Messina véase la obra fundamental de Laloy, 1929-1931. Para un estudio más reciente, al que remitimos para las referencias bibliografías, véase Ribot García, 2002.

${ }^{8}$ Los dibujos de Messina se encuentran en el Archivo General de Simancas (AGS), Mapas, Planos y Dibujos (MPD), 15-117, 1678, 420 x 290 mm, tinta y colores y 05-118, 1678, tinta y colores ocres y amarillos, 420 x 577 mm, y han sido publicados por Ioli Gigante, 1978 y por Giuffrè, 1978: 17.

9 Véanse los siguientes informes AGS, Estado, legajo 3530, n. 78-79, este último ha sido publicado por Giuffrè, 1997: 212.

10 Véase el análisis pormenorizado sobre las propuestas de la ciudadela de Messina realizadas por Sesti y Grunenbergh llevado a cabo en Manfrè, 2016.

11 AGS, Estado, legajo 3527, n. 87.

12 Simancas, AGS, MPD, 12-54, 1679, tinta y colores a la aguada, 417 x 853 mm, publicado por Aricò, 1982: ficha n. 70 .

13 Sobre la importancia del color en las representaciones cartográficas véase San Andrés Moya, De la Roja de la Roja, 2009. Muñoz Cosme, 2016.

14 AGS, Estado, legajo 3527, n. 75, citado en Dufour, 2002: 298.

15 BTMi, Milano, Belgioioso, cartella 267, doc. 318, 1675-1680 ca. pluma, acuarela y lápiz, 420 x 298 mm. El dibujo ha sido señalado en Roncai / Viganò, 2007: 130 y ha sido publicado por primera vez en Manfrè, 2017: 195.

16 AGS, Estado, legajo 3525, n. 118.

17 AGS, Estado, legajo 3499, n. 238.

18 AGS, Estado, legajo 3525, doc. cit. n. 118. 


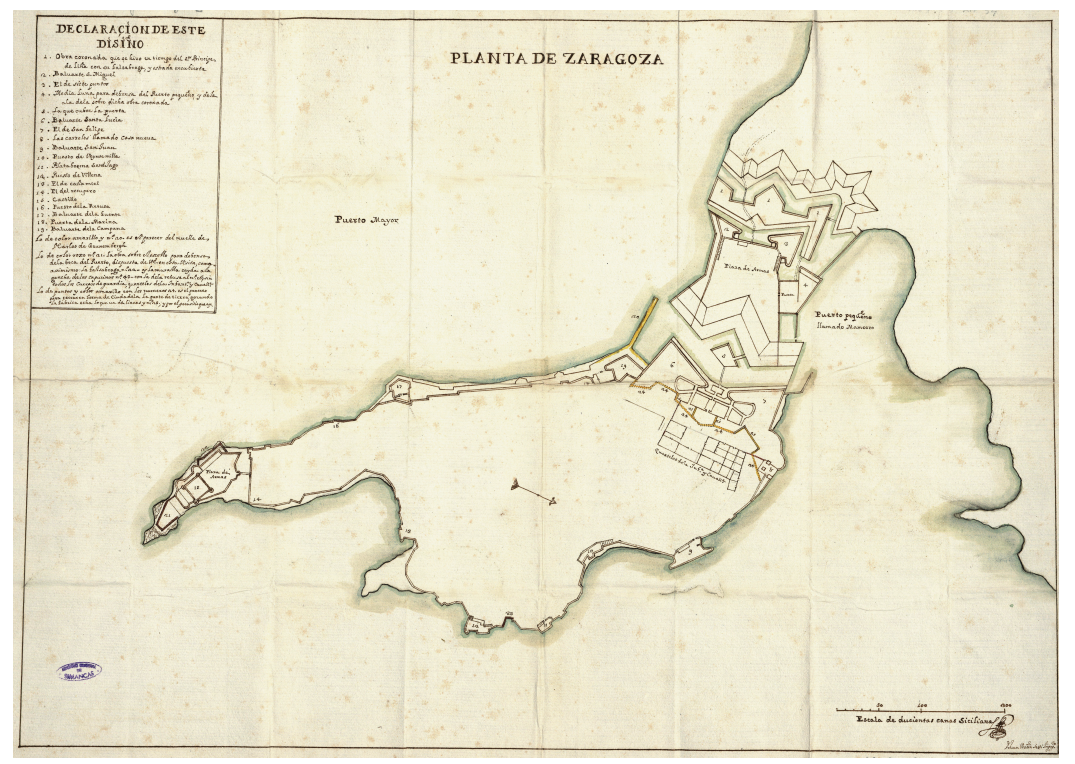

Fig. 1. Giovanni Battista Sesti, Planta de las fortificaciones de Siracusa, 1679, dibujo tinta y colores a la aguada, España, MECD, AGS, Mapas, Planos y Dibujos, 12-54.



Fig. 2. Giovanni Battista Sesti, Planta de las fortificaciones de Milazzo, 1675-1680 ca., dibujo a pluma y lápiz coloreado a acuarela, Milán, Biblioteca Trivulziana, Belgioioso, cartella 267, doc. 318.

que llegó a Palermo el 29 de noviembre de 1678. El 3 de mayo de $1680^{19}$, el conde de Santisteban remitía desde Messina a su soberano una carta advirtiéndole sobre las fortificaciones necesarias para la plaza fuerte de Milazzo. La carta estaba acompañada de una planta de las fortificaciones realizada por el ingeniero Sesti. La revisión de la documentación remitida permite conocer que el objetivo de fortificar Milazzo tampoco se desarrollaría inmediatamente, ya que se encontraba limitado por una cuestión de índole económica y por las dificultades propiamente técnicas de emprender unas fortificaciones de gran envergadura. A este respecto, los argumentos del virrey Santisteban apelaban a la necesidad de fortalecer las ciudades de Augusta y Siracusa y seguir avanzando en las obras de la ciudadela de Messina. A pesar de estos contratiempos, el

19 AGS, Estado, legajo 3527, n. 106. 
virrey Santisteban concibió un plan estratégico para la defensa de Milazzo. El 3 de mayo de 1680 el virrey remitía al Consejo una relación de Milazzo acompañada de una planta realizada por el ingeniero Sesti ${ }^{20}$. Este, el 30 de abril de 1680, escribía desde Messina un informe más prolijo y detallado sobre lo que se había de hacer "para reducirla [Milazzo] en competente defensa"21, y los respectivos costes por cada obra emprendida. Identificados los puntos débiles de las fortificaciones de la ciudad, las intervenciones deberían interesar, entre otros, los baluartes de Villafranca, Ravanal, Fernandina, de San Pamfin, Santana y Capuchinos con sus cortinas, parapetos y terraplenos y posibilitarían el cerramiento de la marina hacia el puerto. Entre estos, como especifica Sesti en su relación, se puso de manifiesto la necesidad de "acabar las dos torres al cabo, y su línea de comunicación”. Con toda seguridad su proyecto apelaba a la necesidad de fortificar un área tradicionalmente débil, donde el enemigo podía atacar fácilmente la península.

Vinculado con este conjunto también estaría el dibujo realizado por Camillo Camilliani (ca. 1550 - ca. 1603) que representa "un forte di bonissima capacità", que debía construirse en Cabo Milazzo 22, y cuyo recinto debía contener el torreón del faro puesto en la extremidad de la península, un proyecto al que Sesti añadió nuevas obras defensivas. Al final de su informe, y refiriéndose a la planta que lo acompañaba, Sesti escribió que "todo lo que se ha de hacer va en el diseño en color amarillo"23. Durante el mes de agosto de 1680 se seguía informando a la corte sobre las "relaciones de las obras que se han de hacer en Melazo los gastos asignando y costa que tendrían y la gente que se halla de guerra en aquella plaza artillería, municiones y pertrechos que hay en ella y juntamente la planta que de su fortificaciones ha formado el ingeniero Sesti"24.

Desafortunadamente, los documentos de Simancas enviados por el virrey Santisteban, no fueron acompañados por la planta relativa a las fortificaciones de Milazzo realizada por Sesti. Sin embargo, los mismos manuscritos acreditan la existencia de un plano que, con toda probabilidad, hay que relacionarlo con el que actualmente se conserva en la biblioteca Trivulziana. Esta identificación postergaría, además, la fecha de ejecución del dibujo, desde el 1675 al año 1680. Por otra parte, como ocurre en casi todos los proyectos de fortificación, es probable que existiesen diferentes copias del diseño enviado desde Sicilia a Madrid, y presentado para ser aprobado por los funcionarios de la corte.

\section{El atlas de la Biblioteca del Palacio Real de Madrid}

En 1707 en Milán se entregaba a la imprenta la editio princeps de la obra Piante delle Città, Piazze e Castelli fortificati in questo Stato di Milano Con le loro Dichiarazioni Date alle Stampe dal Tenente Generale, \& Ingegnere Militare Don Giovanni Battista Sesti. Dedicate all'Altezza Serenissima del Signor Principe Eugenio di Savoia, e Piemonte, Marchese di Saluzzo, Consigliere di Stato, Pressidente del Consiglio Aulico di Guerra, Maresciallo di Campo, Colonnello d'un Regimento de Dragoni, Generale Comandante delle Armi di Sua Maestà Cesarea in Italia, e Cauagliere del Toson d'Oro \&c., [fig. 3] un atlas que fue reimpreso posteriormente, en varias ocasiones, entre 1708 y 1734, siempre en Milán y por el mismo editor Agnelli y destinado a alcanzar una amplia difusión ${ }^{25}$. El volumen, dedicado a François-Eugène de Savoie-Carignano, príncipe de Saboya (1663-1736) ${ }^{26}$ representa, a través de la adopción de una noción de unifor-

20 AGS, Estado, legajo 3527, n.106.

21 AGS, Estado, legajo 3527, n. 108.

22 Scarlata, 1993: 456-457.

${ }^{23}$ AGS, Estado, legajo 3527, doc. cit. n. 108.

24 AGS, Estado, legajo 3527, n. 105.

25 De la obra se han publicado diferentes ediciones facsímil. Para la edición tardía de 1734, señalamos la reedición a cargo de Roncai, 1991.

${ }^{26}$ Para los datos biográficos sobre el príncipe Eugenio véase Braubach, 1963-1965. Para el contexto y la historia militar sobre el príncipe remitimos a Henderson, 1964 y Churchill, 1933-1938. 


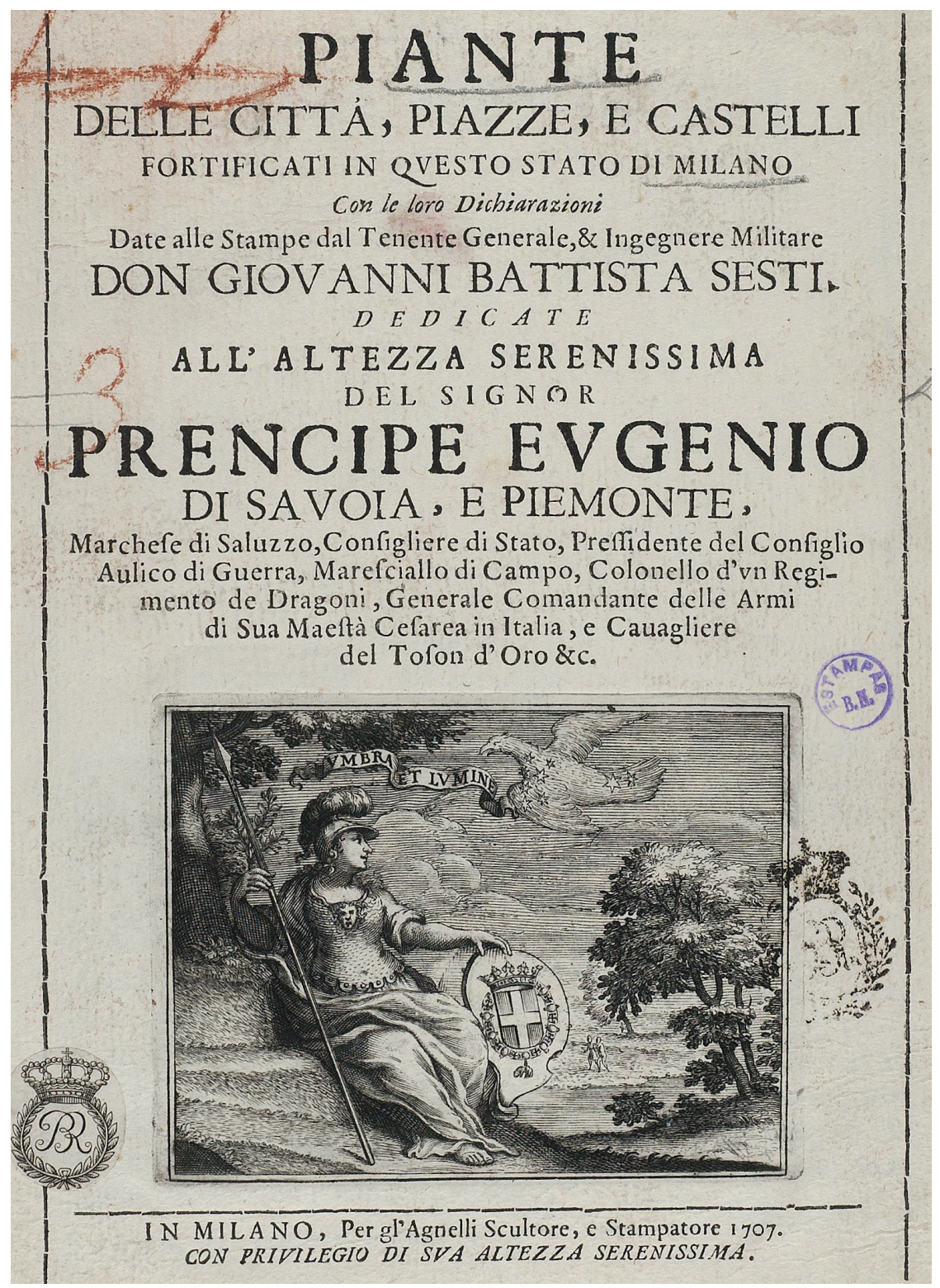

Fig. 3. Giovanni Battista Sesti, "Portada", en Piante delle Città [...], Milán, 1707, grabado calcográfico, Madrid, BNE, ER/2246.

midad en los sistemas de representación, veinticuatro planos de las principales ciudades del Estado de Milán y un mapa del territorio de Milán y sus confines. Esta obra impresa tiene, en realidad, una versión manuscrita, tal vez precedente al ejemplar impreso, que se conserva en la Real Biblioteca de Madrid, con la signatura II/2668 ${ }^{27}$. El atlas titulado Piante delle piazze, $e$ castelli fortificati in questo stato di Milano con le loro dichiarationi delineate da Gio: Bãtta: Sesti, Tenente Generale et Ingegnere militare con dedica Al Altezza Serenissima del Signor Prencipe Eugenio di Savoya, e Piemonte, Marches di Salvuzzo, Consigliere di Stato, Presidente del Consiglio Avlico di Gverra, Maresciallo di Campo, Colonello d'vn Regimiento de Dragoni, General Comandante delle Armi di Sua Maestà Cesarea in Italia, e Cavagliere del Toson d'oro \& c., consta de cincuenta y seis folios (316 x $225 \mathrm{~mm}$ ) y está escrito en letra itálica; en el folio

27 El atlas manuscrito fue dado a conocer a los estudiosos por Dameri / Pozzati, 2018. 


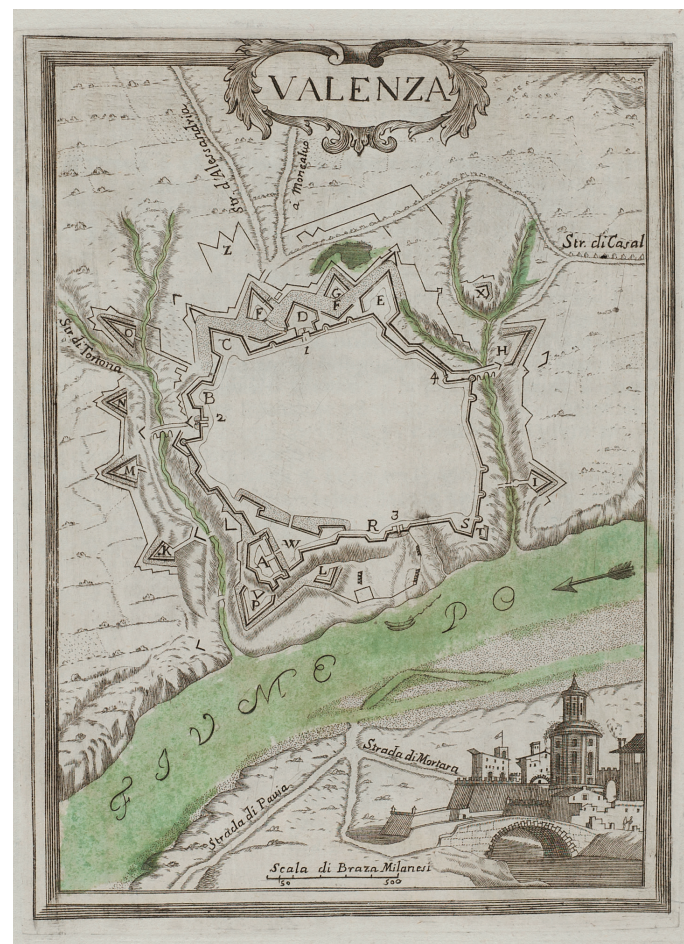

Fig. 4. Giovanni Battista Sesti, "Valenza”, en Piante delle Città [...], Milán, 1707, grabado calcográfico coloreado a la aguada, Madrid, BNE, ER/2246, estampa 8.

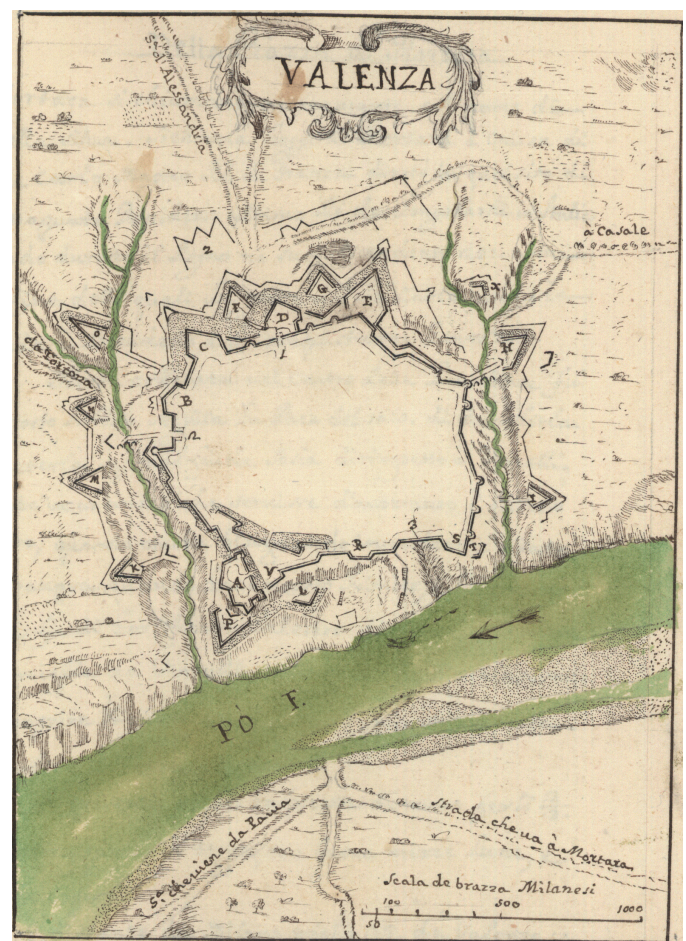

Fig. 5. Giovanni Battista Sesti, "Valenza”, en Piante delle piazze $[. .$.$] , 1$ de enero de 1707 , dibujo a pluma coloreado a la acuarela, Madrid, Biblioteca Palacio Real, Ms. II/2668, f. 22.

tres recto se indica el lugar y la fecha de ejecución, Milán, 1 de enero de 1707. El códice manuscrito demuestra, de nuevo, cómo la labor del ingeniero Sesti se centró en el diseño de ciudades y fortificaciones, en esta ocasión, del Estado de Milán. El manuscrito autógrafo firmado por Sesti en el folio dos recto, después de la dedicatoria, comienza con un dibujo del mapa del territorio de Milán cuya cartela del título está enriquecida con una ornamentación vegetal y de serpientes, mientras que la parte alta del mapa incluye la escala métrica en miglia italiane sostenida por un putto $^{28}$. A continuación, siguen los veintitrés planos de ciudades y castillos de: Milán, castillo Sforzesco de Milán, Pavía, Tortona, castillo de Serravalle, Alessandria, Valenza, Mortara, Novara, Arona, castillo de Domodossola, Como, castillo de Lecco, castillo de Trezzo sull'Adda, Fuerte de Fuentes, Vigevano, Bobbio, Lodi, Pizzighettone y Gera, Cremona, Sabbioneta, castillo de Finalmarina y, por último, el plano de la aldea de Finale Ligure y sus castillos, Gavone y San Juan $^{29}$. Todos los planos, excepto el último donde no viene indicada, incluyen la escala métrica en brazo de Milán. Así mismo, cada plano, dibujado a pluma y coloreado a la acuarela a través de tonos suaves, está precedido por un relato histórico escrito en italiano que acompaña cada una de las imágenes.

Analizar la producción cartográfica manuscrita o impresa, implica adoptar un filtro selectivo debido a que las informaciones proporcionadas solían seleccionarse en función de los intereses del destinatario. Por ello, los testimonios iconográficos elegidos como los más idóneos para la representación de la ciudad y de su territorio, están necesariamente vinculados con el grado de difusión de las informaciones registradas. Como ha sido observado "nelle carte antiche si rappre-

28 Real Biblioteca, Madrid (RB), II/2668, Sesti: f. 7r, 1707, dibujo a pluma y coloreado a la acuarela, 205 x 310 mm, y es el único plegado en 205 x $210 \mathrm{~mm}$.

29 RB, Madrid, II/2668, Sesti: 1707, dibujos a pluma y coloreados a la acuarela, 185 x 135 mm. 


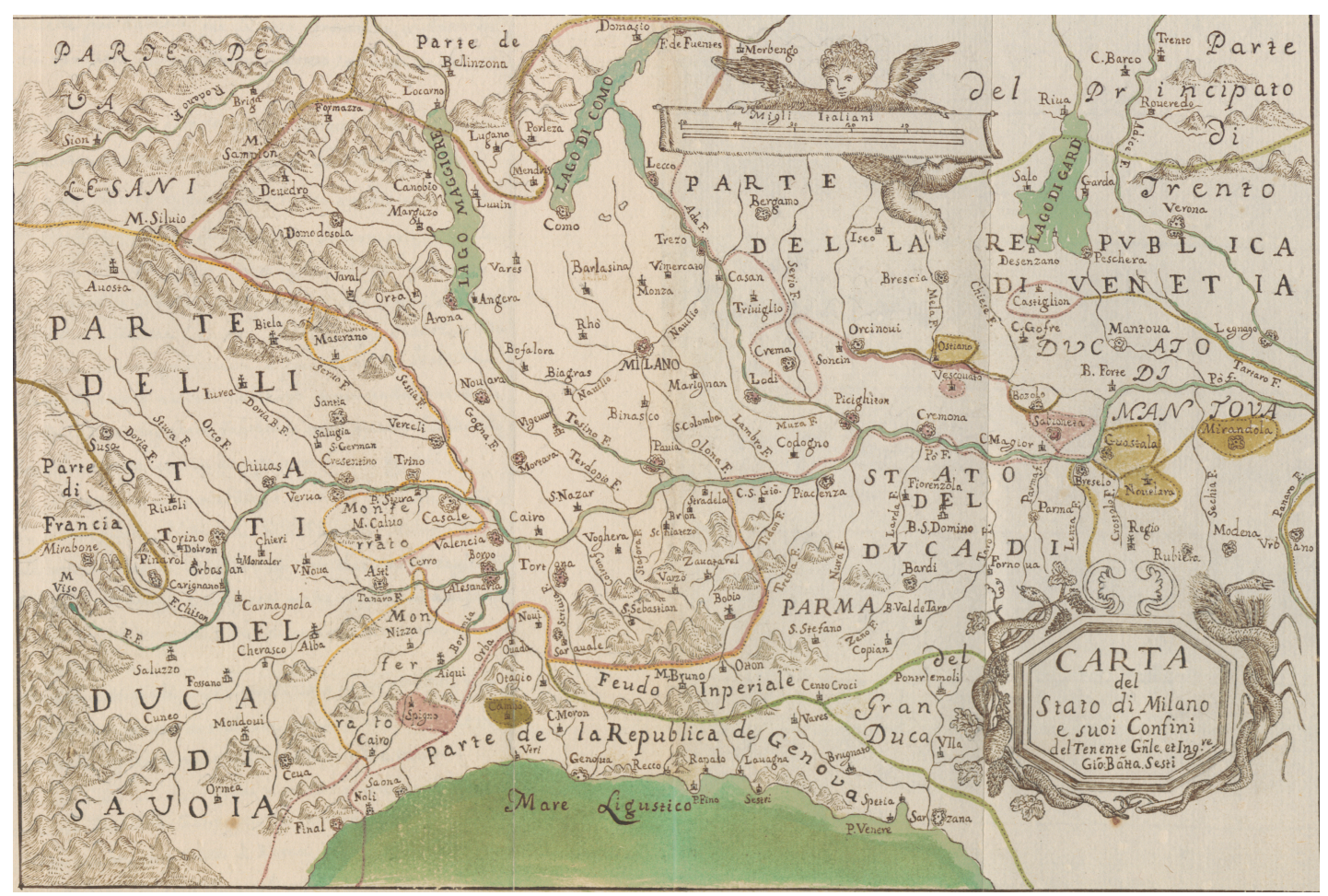

Fig. 6. Giovanni Battista Sesti, “Mapa del territorio de Milán”, en Piante delle piazze [...], 1 de enero de 1707, dibujo a pluma coloreado a la acuarela, Madrid, Biblioteca Palacio Real, Ms. II/2668, f. 7.

senta solo ciò che serve, senza alcuna preoccupazione dei vuoti o delle alterazioni dimensionali”30, hecho que explicaría la existencia de vistas a vuelo de pájaro que representan un edificio o una iglesia en lugar de otro, de planos que descuidan amplios espacios del entramado urbano, y que, por tanto, dejan espacios vacíos deliberadamente, y donde el autor centra su atención en la representación detallada de otros elementos de la ciudad considerados más relevantes como podrían ser, por ejemplo, la muralla y sus puertas. Este discurso es válido, en general, si hablamos de dibujos y proyectos de fortificación manuscritos que, por su naturaleza "secreta", fueron relegados en los archivos militares. En el caso de que esta tipología de información cartográfica pasase de un registro a otro, es decir, del manuscrito a la imprenta —un factor que contribuyó a cimentar el cambio significativo del destinatario o de los destinatarios de dicha información- la representación cartográfica solía estar sujeta a leves o, incluso, a múltiples cambios.

A partir de esta cuestión se indagará en los contenidos de las dos obras, tanto de la impresa como manuscrita, que son muy similares, por no decir que casi idénticos. Cada plano, como hemos señalado, comienza con un somero relato, aunque las esporádicas citas de escritores o historiadores de la Antigüedad y otros eruditos modernos, demuestran un exiguo conocimiento de las fuentes escritas como las descritas por el literato Egidio Tescudo para la ciudad de Domodossola o Paolo Moriggia para el Castillo de Trezzo. Conviene destacar que, respecto al manuscrito, las láminas impresas enfatizan la presencia de vegetación, como árboles, arbustos, personajes y algunas construcciones que corresponden a los puentes que atravesaban las ciudades fluviales del Milanesado, como en el caso de Valenza [figs. 4-5]. A excepción de la lámina y el dibujo que representa el mapa del territorio de Milán y sus confines, [fig. 6] así como una segunda lámina que recoge la planta del castillo de Milán, firmados por Sesti, el resto de los planos impresos y manuscritos carecen de firma.

30 Suitner Nicolini, 1981: 20. 




Fig. 7. Giovanni Battista Sesti, "Planta del Castillo de Milán”, en Piante delle piazze [...], 1 de enero de 1707, dibujo a pluma coloreado a la acuarela, Madrid, Biblioteca Palacio Real, Ms. II/2668, f. 11.
En cuanto a la planta del castillo de Milán disponemos, además, de tres versiones manuscritas casi idénticas: la primera, sin firmar, está incluida en el atlas de Madrid [fig. 7], el segundo dibujo titulado Cast[i]llo de Milano pertenece a la biblioteca Trivulziana [fig. 8] firmado por Sesti ${ }^{31}$, y el tercer ejemplar Pianta del Castello di Milano con suoi Attacchi anno 1707 pertenece a la Biblioteca Nacional de Viena ${ }^{32}$. Al igual que para el plano de Siracusa o Milazzo, también en este caso el color es fundamental para interpretar el dibujo técnico. En este sentido, por debajo de la leyenda del ejemplar de la Trivulziana una nota del ingeniero reza: "Tutto il colorito di Giallo sono li aprochi fatti sino al giorno 6 Marzo 1707”, un apunte que podría legitimar su intervención en Milán, una etapa profesional que aún está por investigar. Sin embargo, en este dibujo — respecto al dibujo análogo que contiene

31 Véase nota 5.

32 Österreichische Nationalbibliothek, Viena (ÖNB), ALB Lade 155,13, dibujo a pluma y coloreado a la acuarela, 300 x 210 mm. A estos tres dibujos del castillo de Milán dedicaremos próximamente un estudio más extenso.

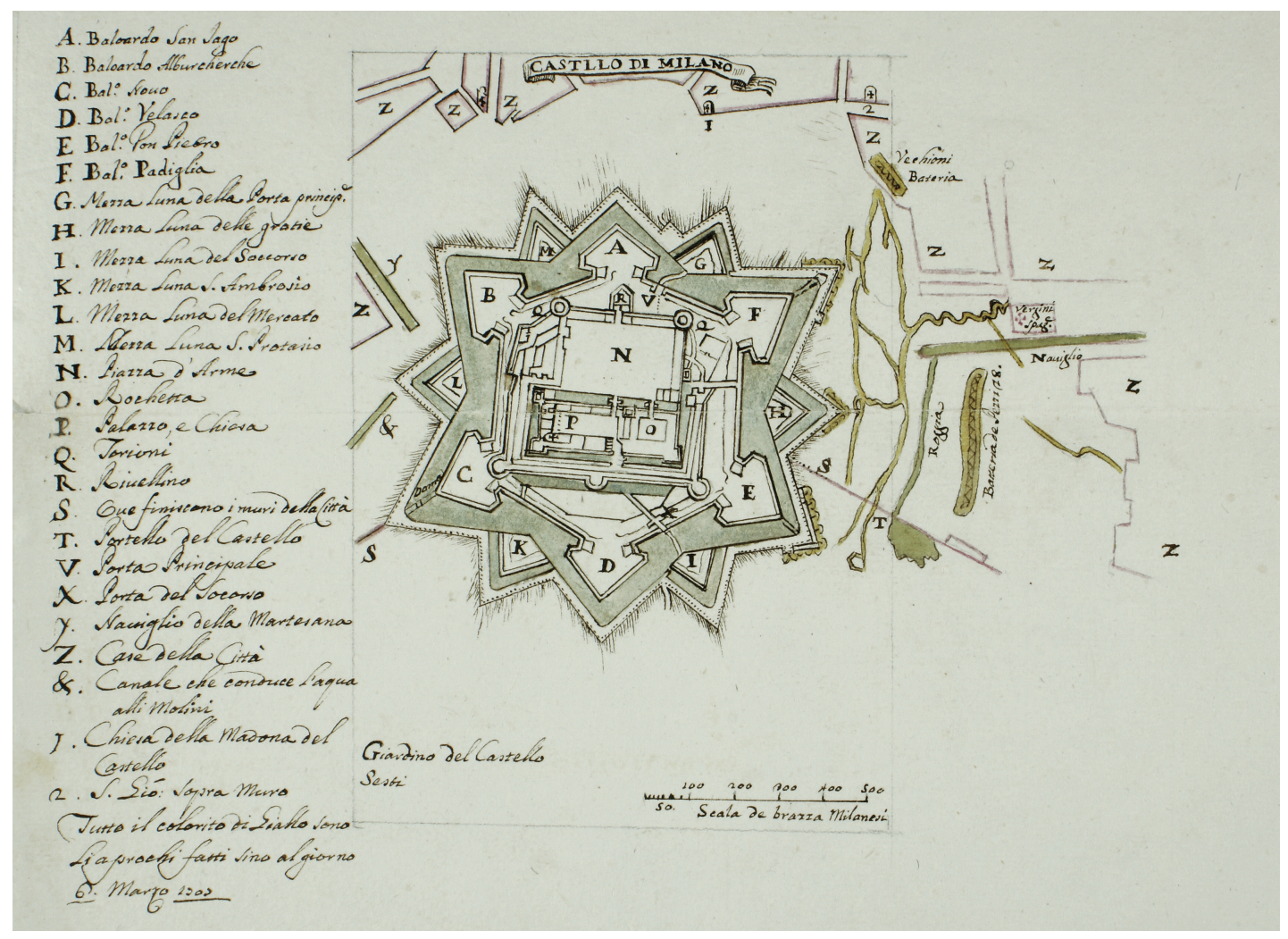

Fig. 8. Giovanni Battista Sesti, Planta del Castillo de Milán, 1707, dibujo a pluma coloreado a la acuarela, Milán, Biblioteca Trivulziana, Belgioioso, cartella 262, doc. 222. 
el atlas donde la fortaleza se representa rodeada férreamente por los ataques o trincheras que iban avanzando hacia sus baluartes - no tiene cabida la representación del territorio que circunda el castillo de Milán, una fortaleza militar transformada durante varios siglos en una moderna ciudadela abaluartada, una machinae de guerra imprescindible para la política estratégica de la monarquía hispánica ${ }^{33}$.

En cuanto a la toponimia, tanto los dibujos como las láminas impresas del atlas están bien documentados. Por lo general, los dibujos con fines militares debían señalar e indicar con exactitud los nombres de los monumentos más importantes de la ciudad como las iglesias, los castillos, los palacios, las fortificaciones y también las obras extra moenia con la nomenclatura de las montañas, caminos o ríos. Sesti optó por utilizar en cada dibujo una leyenda formada por números o letras correlativos, y dispuestos seguidos de los nombres de los elementos, —en su mayoría de carácter militar- que le corresponden. De este modo, el plano lleva solamente el número o letra que le concierne, ofreciendo una imagen muy esmerada. El corpus evidencia, y también cuestiona, la propia función del dibujo que, por un lado, tiende a prefigurar lo que consta en la realidad, y, por otro lado, debería representar lo que había que construir, proyectos que, con frecuencia, no se materializaban y que nunca serían realizados. Para el estudio detallado de cada dibujo del atlas será necesario entrelazar y verificar datos históricos que afectan al desarrollo y la modernización de las fortificaciones representadas, análisis que tendrá lugar en un futuro.

En Milán, Sesti gozó de amplias oportunidades para adquirir o consultar mapas y planos parecidos al que reprodujo en su obra demostrando una notable destreza gráfica y artística. En la dedicatoria del atlas de Madrid, Sesti precisó que había copiado las "Città e Fortezze di questo Stato di Milano" y reiteró su disculpa porque debido a "forzosa necessità tardai à dedicarmi con le copie"34. A pesar del carácter unitario del atlas, la historiadora Maria Luisa Gatti Perer en $1964^{35}$, había indicado que el volumen impreso en 1707 recogía diferentes dibujos que, en parte, provenían de una colección recopilada, entre 1810 y 1819, por el ingeniero Francesco Bernardino Ferrari (1744-1821). La Raccolta Ferrari está compuesta de diferentes manuscritos y de dibujos de ingenieros y arquitectos relacionados con la arquitectura civil, religiosa e hidráulica y que fueron reagrupados en diecinueve tomos cuya cronología abarca desde el siglo XVI hasta el siglo XIX ${ }^{36}$. La fuente o fuentes que inspiraron a Sesti para la copia se encuentran en uno de los tomos de la Raccolta conocido con el título de Cose militari. El tomo, compilado por Ferrari en 1815, consta de cuatro volúmenes manuscritos y uno de dibujos y pertenece al códice T. 189 Sup. El material que lo compone, y que fue consultado por Sesti y posteriormente recopilado por Ferrari, proviene del Colegio de los Ingenieros y Arquitectos de Milán; de todos los dibujos un gran número deben adscribirse al ingeniero Gaspare Beretta (1620-1703), los restantes, entre otros, fueron ideados por los ingenieros Martino Bassi (1542-1591), Tolomeo Rainaldi (1564?-1629), Alessandro Bisnati (1562 - ca. 1617), Francesco Prestino (1610-1648) y Carlo Federico Castiglione (activo como arquitecto militar entre 1728 y 1733) $)^{37}$. A partir de este interesante tomo, la fuente o fuentes de la que copiaba Sesti no resultan completamente desconocidas; el diseño de Pizzighettone o el de Tortona muestran un antecedente en los dibujos realizados por el ingeniero Beretta ${ }^{38}$. Por lo tanto, a primera vista parece tratarse de una obra concebida de este modo, aunque su aspecto externo

\footnotetext{
33 Sobre el castillo de Milán véase Viganò, 2005: 65-79, al que remitimos para la bibliografía citada a lo largo del artículo.

34 RB, Madrid, II/2668, Sesti, 1707: f. 2r.

35 Gatti Perer, 1964b: 131-132.

36 Sobre la Raccolta Ferrari remitimos a Gatti Perer, 1964a; 1965; 2004.

37 Sobre el Tomo “Cose militari” véase el estudio de Gatti Perer 1964b: 128-158. Para un cuadro biográfico de los ingenieros citados remitimos a Bossi / Langé / Repishti, 2007. Sobre Carlo Federico Castiglione véase Colmuto Zanella, 1979.

${ }^{38}$ Raccolta Ferrari, Biblioteca Ambrosiana, Milano (BAMi), Cod. T. 189 Sup. cc. 40 y 70. La biblioteca ha suspendido temporalmente el servicio de reproducción, por lo que ha sido imposible reproducir aquí algunos dibujos muy relevantes para ilustrar este artículo, en concreto el de Pizzighettone y el de Tortona. Sobre Gaspare Beretta y su labor
} 


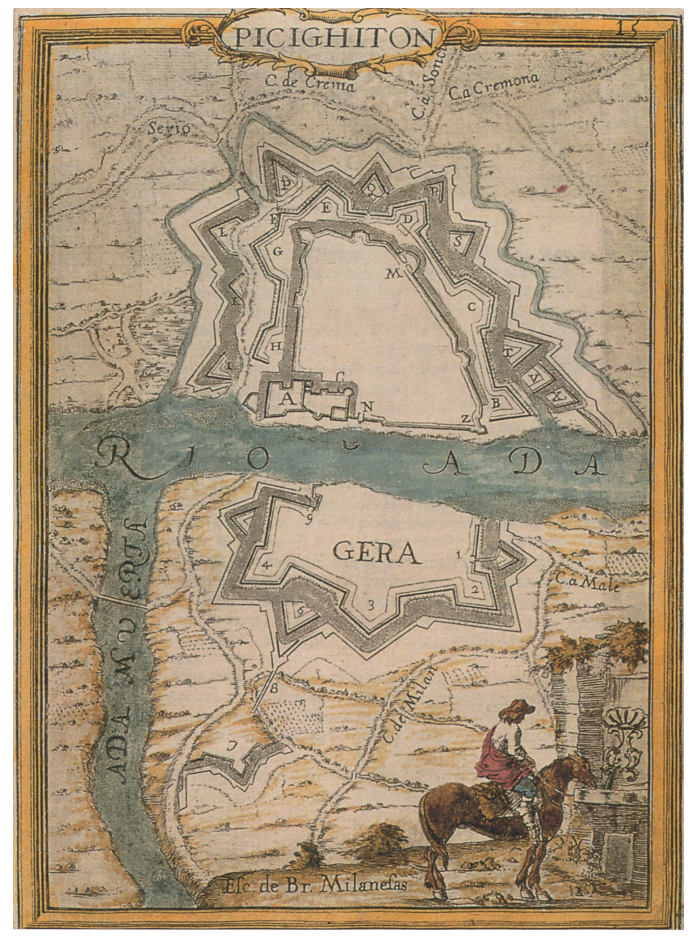

Fig. 9. Joseph Chafrion, "Plano de Pizzighettone y Gera”, en Plantas de las Fortificaciones [...],

Milán 1687, grabado calcográfico coloreado a la aguada, Madrid, BNE, R/2122, estampa 15.

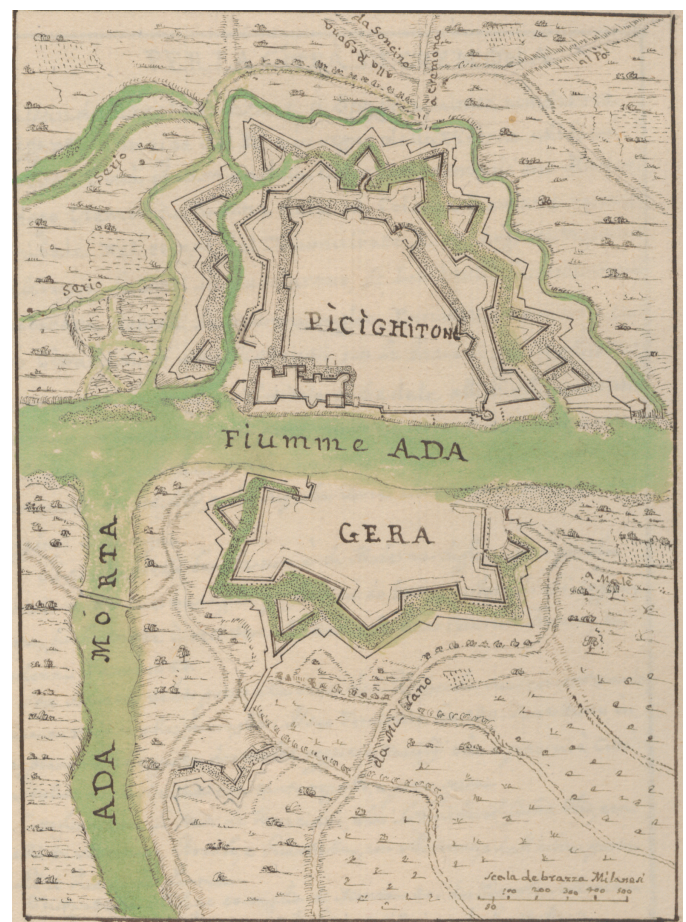

Fig. 10. Giovanni Battista Sesti, "Plano de Pizzighettone y Gera”, en Piante delle piazze [...], 1 de enero de 1707, dibujo a pluma coloreado a la acuarela, Madrid, Biblioteca Palacio Real, Ms. II/2668, f. 46.

sugiere que fue elaborada de una sola vez, por ello es lógico suponer que la operación que llevó Sesti para la realización de la colección consistió en la reducción o ampliación del formato original de los dibujos o láminas utilizados para estandarizar las imágenes. El modus operandi de Sesti no era algo inusual y se acerca a la confección y aparición de los primeros atlas IATO (Italian Assembled To Order) — según una feliz definición de George Beans ${ }^{39}$ recopilaciones cartográficas que se habían formado a partir de la segunda mitad del siglo XVI a través del empleo del abundante material disponible en el mercado tipográfico o en los talleres de los comerciantes de estampas ${ }^{40}$, como los Bertelli de Venecia y el taller de Antonio Lafréry (1512-1577) y sus herederos en Roma ${ }^{41}$. Curiosamente, y como ya ha sido indicado ${ }^{42}$, el atlas de Sesti es un plagio de pleno derecho de la colección de dibujos de elegante factura titulada Plantas de las Fortificaciones de las Ciudades, Plazas y Castillos del Estado de Milán dedicada al rey Carlos II (Milán, 1 de octubre de 1687) y realizada por el capitán de infantería española del tercio de Lombardía e ingeniero militar originario de Valencia, José Chafrion (1653-1698) ${ }^{43}$. De este códice poseemos diferentes copias y sus láminas proceden, según describe Chafrion en la dedicatoria, de los dibujos que el mismo había dibujado y descrito para el Capitán General Antonio López de Ayala y Velasco, conde de Fuensalida, gobernador de Milán

como ingeniero al servicio de la Corona hispánica en Lombardía véase Viganò, 2001: 147-158; un análisis de sus dibujos en Marotta, 2017.

39 Beans, 1938.

40 Un tentativo de análisis comparativo de la amplia producción cartográfica italiana en Bifolco / Ronca, 2014.

${ }^{41}$ Para tener una idea de la producción de mapas en Venecia y Roma véase el gráfico publicado por Woodward, 1997: 52.

42 Viganò, 2007: 62.

43 Sobre Chafrion véase Bossi / Langé / Repishti, 2007: 61-62. 
desde 1686 hasta $1691^{44}$. El códice representa las principales fortificaciones del Milanesado, tal y como se publicaron sucesivamente en 1707 por nuestro autor con pequeños cambios en las cartelas explicativas, así como en las decoraciones utilizadas para adornar los planos y en la representación de las secuencias de los mismos [figs. 9-10].

Por último, suponemos que los dibujos del atlas de Madrid no fueron objeto de un tratamiento de preparación para ser publicados, por el contrario, sería lógico que como norma general se sobrepusiesen sobre una cuadrícula para que el dibujo correspondiente fuese trasladado a una plancha de grabado. Este hecho, por lo tanto, nos conduce a pensar que estamos delante de una versión en limpio pensada especificadamente para ser donada al príncipe Eugenio de Saboya, un objeto creado para ser admirado, según la lógica de la Wunderkammer ${ }^{45}$.

\section{El atlas y el destinatario}

El atlas, muy cuidadoso en sus detalles, responde al deseo de reagrupar en un volumen planos militares ideados por la mano de un único artista. Una práctica habitual en esta época, al menos, si tenemos presente la existencia de atlas muy apreciados, destinados a la ampliación de las colecciones de reyes, príncipes, virreyes o nobles que pertenecían al entourage de la corte española. En este sentido encontramos diferentes ejemplares que contribuyeron a colmar el gusto refinado de sus propietarios a partir del álbum ideado en 1602 por el cosmógrafo Matteo Neroni (ca. 1550-1634), realizado por encargo del gran duque Fernando I de Médicis ${ }^{46}$, el atlas del VII conde de Lemos ${ }^{47}$, el de Gaspar de Haro y Guzmán y Heliche realizado por el pintor italiano Leonardo de Ferrari de $1655^{48}$, o el Atlas de 1687 del ingeniero Lorenzo Possi para Fernando de Médicis, entre otros ${ }^{49}$.

Por lo general, el atlas madrileño puede clasificarse dentro de los denominados atlas militares de la época moderna ${ }^{50}$, a pesar de que, a juicio de Fritz Saxl "le immagini esprimenti un significato particolare nel tempo e nel luogo in cui furono concepite, una volta create hanno il potere magnetico di attrarre altre idee nella propria sfera; e possono essere improvvisamente dimenticate e poi richiamate alla memoria dopo secoli di oblio" 51 , palabras que nos sugieren cómo el mundo de la cartografía puede ser interpretado a partir de diferentes claves de lectura. Algunos de estos ejemplares, de hecho, podrían entrar en pleno derecho en el intercambio de regalos diplomáticos ${ }^{52}$, una práctica que establecería nuevas hipótesis sobre este hábito y la elección del panorama cartográfico existente entre el mecenas y el autor ${ }^{53}$. Por otro lado, no hay que olvidar que la producción cartográfica implica la existencia de un cliente específico y la presencia de una

44 El ejemplar coloreado y consultado se encuentra en la Biblioteca Nacional de España, Madrid (BNE), R/2122, los restantes ejemplares se encuentran, entre otros, en la Biblioteca Nazionale Braidense de Milán (BBM), sezione Manoscritti 3.1.K5 (fechada agosto de 1687) y en la Bibliothèque Nationale de France, París (BNF) a la sign. Rés. K 1.371 (fechado octubre de 1687). Sobre el atlas de Chafrion véase Dameri / Pozzati, 2019.

45 Schlosser, 1988.

${ }^{46} \mathrm{El}$ atlas, que se conserva en la Biblioteca Nazionale de Florencia, en la sign. Fondo nazionale II.I.281, ha sido estudiado por Lamberini, 2013.

${ }^{47}$ La fecha de ejecución no está clara, aunque posiblemente fue realizado entre 1610 - post. 1616. Véase Brunetti, 2006: 14.

48 Sánchez Rubio / Testón Núñez / Sánchez Rubio, 2004. El atlas se guarda en el Archivo Militar de Estocolmo, el Krigsarkivet, en la sección Handritade kartverk, volumen 25.

49 Sánchez Rubio / Sánchez Rubio / Testón Núñez, 2014. El atlas actualmente se guarda en la Biblioteca del Museo Galileo de Historia de la Ciencia de Florencia (MED) G. F. 44.

50 Warmoes / D’Orgeix/ van den Heuvel (eds.), 2003.

51 Saxl, 1965: 2-3.

52 Goldberg, 1996.

53 El nacimiento de estas colecciones cartográficas o atlas no ha sido suficientemente estudiado por parte de los historiadores. Queda por investigar si fueron los reyes, príncipes o coleccionistas los que encargaron estos atlas o, más bien, si fueron una iniciativa de carácter comercial. Por último, habría que profundizar también en las diferentes fun- 
coyuntura social que impulsase el mecenazgo y que, a nuestro juicio, fue imprescindible, en parte, debido a que los atlas tienen un alto coste, tanto en lo que concierne a la organización del trabajo, como en la estructura editorial.

Eugenio, educado en sus primeros años de vida en territorio francés y, en concreto, en Versalles, creció bajo las enseñanzas de su tutor, Joseph Sauveur $(1653-1716)^{54}$, un distinguido matemático y físico educado en el colegio jesuita de La Flèche y en las escuelas parisinas de filosofía y teología, y por un segundo tutor, el jansenista Jacques-Bénigne Bossuet (1627-1704). La influencia de Sauver canalizó las habilidades y aptitudes del príncipe en el estudio de las matemáticas, de la arquitectura militar, de la medicina y en el ámbito de los principios de fortificación de Sébastien Le Prestre, marqués de Vauban (1633-1707). De hecho, fue el mismo Sauveur quién acercó el príncipe al estudio del arte de las fortificaciones a través de un manuscrito que él mismo había redactado en Versalles, donde se analizaban los elementos geométricos y de fortificación de Vauban ${ }^{55}$. El periodo formativo y las habilidades del príncipe Eugenio, así como su predisposición hacia la lectura de textos de matemática y fortificación ${ }^{56}$, o el intento de fundar, a finales de 1717, una academia militar en Viena para futuros ingenieros bajo la dirección del ingeniero italiano Leandro Anguissola (1653-1720) coadyuvado por el subdirector y conterráneo ingeniero Giovanni Giacomo Marinoni (1676-1755), manifiestan su gran interés hacia los temas militares o cartográficos ${ }^{57}$.

La implicación de un hombre del aparato estatal, el príncipe Eugenio, importante mecenas, coleccionista y destinatario del atlas, arroja luz sobre esta faceta y también en su vertiente como bibliófilo ${ }^{58}$, dado que su propia biblioteca contaba con ejemplares como la Tabula Peutingeriana ${ }^{59}$, el Atlas maior de 1665 de Joan Blaeu, y su versión francesa de 1667 y los tres atlas, Novus, Coelestis y Maritimus, de Joan Jannsonius ${ }^{60}$. En el mismo contexto se justificaría la probable adquisición de la colección de dibujos preparatorios del flamenco Antoon van den Wijngaerde (ca. 1512/1525-1571), un gran álbum formado por setenta y nueve hojas, que contiene también copias de dibujos realizados en 1587 y algunos otros realizados por George Hoefnagel (15421600), muy conocido por haber ilustrado el atlas de Georg Braun y Franz Hogenberg, Civitates orbis terrarum ${ }^{61}$. Igualmente, entre las obras gráficas de su espléndida biblioteca se indicaba el atlas iluminado Descripion de España y de las costas y puertos de sus reynos ${ }^{62}$, concluido en 1634 bajo la dirección del cosmógrafo e ingeniero Pedro Texeira (ca. 1595-1662), un proyecto que recreaba, a través de representaciones cartográficas y corográficas, los territorios de la península ibérica donde Texeira había trabajado al servicio de Felipe IV, quién encargó la obra63.

No obstante, en el apartado titulado Artes. Architettura Militaris... del primer volumen del Catalogus librorum bibliothecae principis Eugenii de Sabaudia no tenemos constancia de la

ciones que cumplían estos lujosos códices. A este respecto véanse las reflexiones, que pueden servir como punto de partida, en Woodward, 2007a; 2007b.

54 Bianchi, 2012a: 16-17.

55 Feola, 2014: 744-745.

56 A este respecto véase los libros de matemática y de arquitectura militares anotados en el Volumen I del Catalogus, 1700-1799, ÖNB, Cod. 13963, fols: 188r-208v y 238r-243v.

57 Sobre la academia de ingeniería, que abrió en 1718, véase Gatti, 1901: 58, 60-90.

58 A su muerte, en 1736, la biblioteca contaba con dieciséis mil volúmenes, y 237 manuscritos. Sin embargo, al día de hoy no existe un estudio exhaustivo sobre la biblioteca del príncipe Eugenio y los diferentes catálogos de su biblioteca. Remitimos a las parciales investigaciones de Ricuperati, 2012: 77-88. Fasoli, 2006: 241-267 y a la recién aportación de Feola, 2014: 758-763, 773-787, cuyo análisis intenta aportar una nueva perspectiva sobre la colección de libros del príncipe. Para los libros en lengua española véase la tesis doctoral de Nieto Nuño, 1988: 237-265.

59 Catalogus, 1700-1799: ÖNB, Cod. 13965, Volumen III: f. 1517r. El mapa se encuentra en la ÖBN, Codex Vindobonensis 324 .

60 Catalogus, 1700-1799: ÖNB, Cod. 13964, Volumen II: f. 781r.

61 Galera i Monegal, 1998: 53. Sobre las vistas de Wyngaerde véase la edición facsímil de Kagan (ed.), 1986.

62 Nieto Nuño, 1988: 267. El único volumen del catálogo de la biblioteca del príncipe Eugenio donde se alude al atlas de Texeira, indicado como "Descripcion de España y de las costas”, es la copia del catálogo realizada por Etienne Boyer después de 1736, Index, ÖBN, Cod. 14379: f. 253r.

63 Sobre el Atlas de Texeira véase Pereda / Marías, 2002. Pereda / Marías, 2004. 
versión manuscrita del Atlas madrileño de Sesti, en cuanto solamente viene citada la versión impresa de $1707^{64}$. Tal vez, esta ausencia abre la posibilidad de que esta colección cartográfica manuscrita nunca estuvo en posesión de Eugenio.

El encargo por parte del príncipe Eugenio se enmarca en un momento histórico muy concreto ya que, en el norte de Italia, el príncipe consiguió derrotar a los franceses que sitiaban Turín liberando, en 1706, la ciudad del asedio, hazaña que determinó también la conquista de Milán ${ }^{65}$. Este acontecimiento le permitió ser nombrado gobernador general del ducado de Milán, entre 1706 y 1716, y de este modo, el encargo del atlas se convirtió en una fuente de orgullo, mediando en la transición de la gestión política del Estado de Milán que pasó a ser tutelado por los austriacos, después de la presencia española.

A raíz de las consideraciones anteriores, y atendiendo al vínculo que Sesti estableció entre el documento cartográfico y la intencionalidad artística y decorativa del mismo, es fácil suponer que el álbum de Madrid respondiese a una petición específica del propietario, una obra considerada, con toda probabilidad, y desde el principio, como material susceptible de ser coleccionado. Un análisis comparativo entre las ilustraciones de la versión manuscrita e impresa - donde las escasas variaciones de contenido se reflejan sobre todo en el aparato decorativo, como las cartelas o las cornisas que enmarcan las leyendas de cada ciudad- permiten dudar del alto valor estratégico del álbum que fue inmediatamente impreso para su divulgación. A este respecto, conviene recordar que la política tradicional de sigilo impuesta sobre la cartografía oficial española, especialmente por su valor estratégico, no preveía su publicación. Según palabras de Tácito en sus Annales, los mapas se consideraban como arcana imperii, un concepto que se trasladó a los mapas españoles ${ }^{66}$. En este sentido, resultan muy reveladoras las palabras de Chafrion dirigidas al "Erudito", ya fuese este un amigo o un enemigo ${ }^{67}$. En este último caso, parece que el ingeniero valenciano dio por hecho que el enemigo conociese personalmente, o a través de algún tipo de relación escrita, las plantas de las ciudades descritas y aunque a través de las láminas podría tener una idea de su figura y de sus obras defensivas, no tendría ninguna medida de las fortalezas representadas, ni podría descubrir sus defectos ni tampoco lo que contenía la plaza fuerte en su interior que, según parece, era la información más ventajosa que podría ser utilizada por parte del enemigo, con el fin de atacar la fortaleza. De hecho, la relación que acompaña las urbes de todos los ejemplares aquí mencionados, es una descripción muy genérica y que atañe principalmente a la fundación de cada ciudad, su etimología, la fertilidad de la tierra y su clima.

De este modo, cabría una reflexión relacionada con el atlas de Sesti que, al ser un plagio, se le podría aplicar la misma argumentación esclarecida por Chafrion que justificaría la inmediata publicación del manuscrito de Madrid. Sesti sigue renunciando a la utilidad y al valor estratégico volviendo a convertir los diseños de las fortificaciones del ducado en simples dibujos geométricos que carecen, según argumentaba Chafrion, de referencias útiles y prácticas para los enemigos eludiendo, de este modo, la política de sigilo de la Corona, y convirtiendo el atlas en un objeto preciado de colección.

La documentación utilizada hasta la fecha no arroja luz sobre los motivos efectivos que pudieron llevar al príncipe a encargar el atlas, sometido, probablemente, a dúplices interpretaciones, por un lado, a las leyes de la utilidad y, por otro, a los códigos estéticos. El príncipe Eugenio fue un hábil estratega y de gusto refinado que amaba celebrar sus propias empresas bélicas ${ }^{68}$. El encargo respondería a una actitud celebrativa de sus victorias que se manifestó en los años posteriores a través de otros encargos artísticos y que está perfectamente plasmado en el ciclo Hu-

64 "Piante delle Città, Piazze e Castelli fortificati dello Stato di Milano, colle loro dichiarazioni, da D. Giov: Batt: Sesti. in Milano 1707. Gli Agnelli”, en Catalogus, 1700-1799, ÖNB, Cod. 13963, Volumen I: f. 239r.

65 Del Nigro, 2007. Para un cuadro histórico véase Bianchi, 2012b, en particular los capítulos 4 y 6, respectivamente sobre el príncipe Eugenio y el asedio de 1706.

66 Parker, 2001, capítulo 4. Kagan, 2002: 63.

67 Chafrion, 1687: 4.

68 Arnaldi di Balme, 2012: 190. 
chtenburg, que recrea diez pinturas que ilustran la victoria de la batalla de Zenta sobre los turcos en 1697 y la de Belgrado de 1717.

Coleccionismo y razones políticas han alentado la circulación de estos atlas que representaban las fortalezas de los dominios españoles, sin excluir otras instancias, que encuentran justificación en el ámbito auto-celebrativo, a la vez que propagandístico, de la clase más poderosa o, en un contexto más general, en el marco político-representativo. El atlas y su contenido demuestran cómo una temática específica, y que está considerada como limitada por su uso práctico y su destino como una forma de conocimiento político-militar, en realidad, puede tener un gran valor simbólico, sin excluir, con ello, la importancia del dibujo con fines estratégicos. El álbum de Sesti muestra las nociones del prestigio y la riqueza que enfatizan el estatus social del propietario quien, a pesar de la ausencia de pruebas irrefutables, participó en la ideación y realización del producto y de su contenido como expresión de las buenas prácticas de gobierno.

\section{Apéndice ${ }^{69}$}

Indice delle Piazze, Città, e Castelli, che sono nel libro

1. La carta Generale del Stato di Milano, e suoi confini

2. Città di Milano

3. Castello di Milano

4. Città di Pavia

5. Città di Tortona

6. Castello di Saravalle

7. Città di Alessandria

8. Piazza di Valenza

9. Piazza di Mortara

10. Città di Novara

11. Piazza d'Arona

12. Castello di Domodossola

13. Città di Como

14. Piazza, e Castello di Lecco

15. Castello di Trezzo

16. Forte de Fontes

17. Città di Vigevano

18. Città di Bobio

19. Città di Lodi

20. Piazza di Pizighittone, e Gera

21. Città di Cremona

22. Piazza di Sabioneda

23. Castelli della Marina di Finale

24. Castel Gavone, San Giovanni, e Borgo di Finale

\section{BIBLIOGRAFÍA}

Aricò, Nicola (1982): “Sicilia: ragioni storiche della presenza”. En: Principe, Ilario (ed.): Il progetto del disegno: città e territori italiani nell’Archivo General di Simancas. Reggio Calabria: Casa del Libro Editrice, pp. 145-149.

69 RB, Madrid, II/2668, Sesti, 1707: f. 5r. Transcripción del índice del atlas. 
Arnaldi di Balme, Clelia (2012): “Il principe stratega. Le celebrazioni delle vittorie”. En: Spantigati, Carla E. (ed.): I quadri del Re. Le raccolte del principe Eugenio condottiero e intellettuale. Collezionismo tra Vienna, Parigi e Torino nel primo Settecento. Milán: Silvana Editoriale Spa, pp. 190-191.

Beans, George H. (1938): Some Sixteenth Century Watermarks found in Maps Prevalent in the «IATO» Atlases. Jenkintown: Gerge H. Beans Library.

Bianchi, Paola (2012a): "Eugenio di Savoia. Il profilo europeo e le icone del principe guerriero". En: Spantigati, Carla E. (ed.): Le raccolte del principe Eugenio condottiero e intellettuale. Collezionismo tra Vienna, Parigi e Torino nel primo Settecento, Milán: Silvana Editoriale Spa, pp. 13-25.

Bianchi, Paola (2012b): Sotto diverse bandiere. L'internazionale militare nello Stato sabaudo d'antico regime. Milán: Franco Angeli.

Bifolco, Stefano / Ronca, Fabrizio (2014): Cartografia rara Italiana: XVI secolo. L'Italia e i suoi territori. Catalogo ragionato delle carte a stampa. Roma: Ed. Antiquarius.

Bossi, Paolo / Langé, Santino / Rephisti, Francesco (2007): Ingegneri ducali e camerali nel ducato di Milano e nello Stato di Milano (1450-1706). Dizionario biografico. Florencia: Edifir Ed.

Braubach, Max (1963-1965): Prinz Eugen von Savoyen: eine Biographie. Viena: Verlag für Geschichte und Politik, 5 vols.

Brunetti, Oronzo (2006): L'ingegno delle mura: l'Atlante Lemos della Bibliothèque Nationale de France. Florencia: Edifir.

Catalogus librorum bibliothecae principis Eugenii de Sabaudia, Österreichische Nationalbibliothek. Viena: 1700-1799. Vols. I-IV, ms. Cod. 13963-13966.

Chafrion, José (1687): Plantas de las Fortificaciones de las Ciudades, Plazas y Castillos del Estado de Milán. Milán: s.n.

Churchill, Winston (1933-1938): Marlborough: His Life and Times. Londres: G. G. Harrap, 4 vols.

Colmuto Zanella, Graziella (1979): Dizionario Biografico degli Italiani, Carlo Federico Castiglione, ad vocem, vol. 22.

Dameri, Annalisa / Pozzati, Alice (2018): “Tra Spagna e Austria: Giovanni Battista Sesti ingegnere militare”. En: Marotta, Anna / Spallone, Roberta (eds.). Defensive Architecture of the Mediterranean, Vol. VII. Turín: Politecnico di Torino, pp. 95-102.

Dameri, Annalisa / Pozzati, Alice (2019): "Disegnare la città fortificata: copie e citazioni: Joseph Chafrion e gli atlanti del XVII secolo”. En: Disegnare idee immagini, año 30, nº 58, pp. 60-69.

Del Nigro, Piero (2007): “Eugenio di Savoia: la fortuna italiana del principe tra Sei e Settecento”. En: 1706. L'ascesa del Piemonte verso il Regno. Turín: Centro Studi Piemontesi, pp. 53-72.

Dufour, Liliane (2002) : "Du château à la citadelle: la transformation des châteaux siciliens et la construction de la citadelle de Messine”. En: Blieck, Gilles (ed.). Le château et la ville: conjonction, opposition, juxtaposition (XVe-XVIIe siècle). París: CTHS, pp. 291-304.

Fasoli, Vilma (2006): “La biblioteca di Eugenio. Scienza e arte della guerra”. En: Balani, Donatella, Benedetto, Stefano A. (eds.). Torino 1706. Turín: Collana Blu, pp. 241-267.

Feola, Vittoria (2014): “Prince Eugene and his library. A preliminary analysis...”. En: Rivista Storica Italiana, año CXXVI, fascículo III, pp. 742-787.

Galera i Monegal, Montserrat (1998): Antoon van den Wijngaerde, pintor de ciudades y de hechos de armas en la Europa del Quinientos. Madrid: Institut Cartogràfic de Catalunya.

Gatti, Friedrich (1901): Geschichte der K.K. Ingenieur-und K.K. Genie-Akademie: 1717-1869. Viena: Braumüller in Komm.

Gatti Perer, Maria Luisa (1964a): “Fonti per l'architettura milanese dal XVI al XVIII secolo: Francesco Bernardino Ferrari e la sua raccolta di documenti e disegni”. En: Arte lombarda, Venecia, IX, 1, pp. 173-222.

Gatti Perer, Maria Luisa (1964b): "Fonti per l’architettura milanese dal XVI al XVIII secolo: Francesco Bernardino Ferrari e la sua raccolta di documenti e disegni”. En: Arte lombarda, Venecia, IX, 2, pp. 128-158.

Gatti Perer, Maria Luisa (1965): “Fonti per l’architettura milanese dal XVI al XVIII secolo: Francesco Bernardino Ferrari e la sua raccolta di documenti e disegni”. En: Arte lombarda, Venecia, X, 1, pp. 139-155.

Gatti Perer, Maria Luisa (2004): "Per l'avanzamento degli studi sulla difesa della Lombardia spagnola. Il contributo della Raccola Ferrari”. En: Colmuto Zanella, Graziella / Roncai, Luciano (eds.): La difesa della Lombardia Spagnola. Cremona: Ronca, pp. 23-36.

Goldberg, Edward L. (1996): “Artistics relations between the Medicis and the Spanish Court, 1587-1621”. En: Burlington Magazine, Londres, 138, 1115, pp. 105-114.

Giuffrè, Maria (1978): "La Sicilia fuori di Sicilia. Note e considerazioni sull'assetto degli spazi storici dal XVI al XIX secolo”. En: Parametro, Faenza, IX, 67, pp. 12-19.

Giuffrè, Maria (1997): “L'isola e il mare: il porto di Messina e altri porti”. En: Simoncini, Giorgio (ed.): Sopra i porti di mare. Vol. IV. Sicilia e Malta. Florencia: Leo Olschki, pp. 193-238.

Henderson, Nicholas (1964): Prince Eugene of Savoy. Nueva York: Weidenfeld and Nicolson.

Index Autorum, Interpretum, Commentator; Adnotatorum, Emendatorum, ac Editorum in Catalogo Bibliotheca Ser.mi Principis Eugenij è Sabaudia Complexorum, ordine alphabetico dispositus, Österreichische Nationalbibliothek. Viena: 1736 ca. Ms. Cod. 14379.

Ioli Gigante, Amelia (1978): "La costruzione della cittadella di Messina attraverso alcune carte dell’Archivio General di Simancas (Valladolid)”. En: Archivio Storico Messinese, Messina, 3, 29, pp. 45-58. 
Kagan, Richard L. (ed.) (1986). Ciudades del Siglo de Oro. Las vistas españolas de Anton van den Wyngaerde. Madrid: El Viso.

Kagan, Richard L. (2002): “Arcana imperii: mapas, ciencia y poder en la corte de Felipe IV”. En: Pereda, Felipe, Marías, Fernando (eds.): El Atlas del Rey Planeta La “Descripción de España y de las costas y puertos de sus reinos” de Pedro Texeira (1634). Madrid: Nerea, pp. 49-69.

Laloy, Emile (1929-1931): La révolte de Messine, l'expédition de Sicile et la politique française en Italie, 1674-1678, avec des chapitres sur les origines de la revolte, 1648-1674, et sur le sort des exilés, 1678-1702. París: Libraire C. Klincksieck, 3 vols.

Lamberini, Daniela (2013): Il mondo di Matteo Neroni, cosmografo mediceo. Florencia: Edifir.

Manfrè, Valeria (2016): "El virrey Francisco de Benavides, IX conde de Santisteban y el diseño del territorio: arquitecturas defensivas e ingenieros en Messina”. En: Piazza, Stefano (ed.): La Sicilia dei viceré nell'età degli Asburgo (15161700). La difesa dell'isola, le città capitali, la celebrazione della monarchia. Palermo: Caracol, pp. 227-246.

Manfrè, Valeria (2017): “Ingenieros itinerantes: el caso de la familia Sesti”. En: Echarri Iribarren Víctor (ed.): Defensive Architecture of the Mediterranean. XV to XVIII Centuries. Vol. V. Alicante: Universitat d'Alacant, pp. 191-197.

Marotta, Anna (2017): "Disegni di Gaspare Beretta nel territorio europeo per la difesa, nei secoli XVII e XVIII”. En: Echarri Iribarren Víctor (ed): Difensive Architecture of the Mediterranean XV to XVIII Centuries, Vol. V. Alicante: Universitat d'Alacant, pp. 175-182.

Muñoz Cosme, Alfonso (2016): "Instrumentos, métodos de elaboración y sistemas de representación del proyecto de fortificación entre los siglos XVI y XVIII”. En: Cámara Muñoz, Alicia (ed.) (2016): El dibujante ingeniero al servicio de la monarquía hispánica. Siglos XVI-XVIII. Madrid: Fundación Juanelo Turriano, pp. 32-38.

Nieto Nuño, Miguel (1988): Fondos hispánicos en la biblioteca Nacional de Viena. Tesis doctoral: Universidad Complutense de Madrid.

Parker, Geoffrey (2001): El éxito nunca es definitivo. Imperialismo, guerra y fe en la Europa moderna. Madrid: Taurus.

Pereda, Felipe / Marías, Fernando (eds.) (2002): El Atlas del Rey Planeta La "Descripción de España y de las costas y puertos de sus reinos" de Pedro Texeira (1634). Madrid: Nerea.

Pereda, Felipe / Marías, Fernando (2004): “De la cartografía a la corografía: Pedro Texeira en la España del Seiscientos”. En: Ería, Oviedo, 64-65, pp. 129-157.

Ribot García, Luis (2002): La monarquía de España y la guerra de Messina (1674-1678). Madrid: Actas.

Ricuperati, Giuseppe (2012): "Il principe Eugenio, il barone di Hohendorf e le loro biblioteche alle origini del Triregno di Pietro Giannone”. En: Spantigati, Carla E. (ed.), Le raccolte del principe Eugenio condottiero e intellettuale. Collezionismo tra Vienna, Parigi e Torino nel primo Settecento. Milán: Silvana Editoriale Spa, pp. 77-88.

Roncai, Luciano (ed.) (1991). En: Sesti, Giovanni Battista: Piante delle Città, Piazze, e Castelli fortificati in questo Stato di Milano. Cremona: Turris.

Roncai, Luciano / Viganò, Marino (2007): “Giovanni Battista Sesti”. En: Bassi, Paolo / Langé, Santino / Repishti, Francesco (eds.). Ingegneri ducali e camerali nel ducato e nello stato di Milano (1450-1706). Dizionario Biobibliografico. Florencia: Edifir, pp. 129-130.

San Andrés Moya, Margarita / De la Roja de la Roja, José Manuel (2009): "El color y su significado en los documentos cartográficos del Cuerpo de Ingenieros Militares del siglo XVIII”. En: Ge-conservación, Madrid, 0, pp. 141-146.

Sánchez Rubio, Carlos / Sánchez Rubio, Rocío / Testón Núñez, Isabel (2014): El Atlas Medici de Lorenzo Possi. 1687. Piante d'Estremadura, e di Catalogna. Badajoz: 4 Gatos.

Sánchez Rubio, Rocío / Testón Núñez, Isabel / Sánchez Rubio, Carlos M. (2004): Imágenes de un imperio perdido: el atlas del Marqués de Heliche: plantas de diferentes plazas de España, Italia, Flandes y Las Indias. Mérida-Badajoz, 4 Gatos.

Saxl, Fritz (1965): La storia delle immagini. Bari: Laterza.

Scarlata, Marina (1993): L'opera di Camillo Camiliani. Roma: Istituto Poligrafico e Zecca dello Stato.

Schlosser, Julius von (1988): Las cámaras artísticas y maravillosas del renacimiento tardío. Madrid: Akal.

Sesti, Giovanni Battista (1707): Piante delle piazze, e castelli fortificati in questo stato di Milano con le loro dichiarationi delineate da Gio: Bãtta: Sesti (...), RB, Ms. II/2668.

Suitner Nicolini, Gianna (1981): "L'impostazione del catalogo e del metodo di lettura delle mappe storiche”. En: Le mappe e i disegni dell'Archivio Gonzaga di Mantova. Verona: Cortella, pp.13-30.

Vesco, Maurizio (2015): "Ingegneri militari nella Sicilia degli Asburgo: formazione, competenze e carriera di una figura professionale tra Cinque e Seicento". En: Rodríguez-Navarro Pablo (ed.): Defensive Architecture of the Mediterranean. XV to XVIII centuries. Vol. I. Valencia: Universitat Politècnica de València, pp. 223-230.

Viganò, Marino (2001): "Le portefeuille de Gaspare Beretta (1620-1703) à la Bibliothèque Trivulziana de Milan: plans et mémoires pour servir l’Espagne”. En: Maroteaux, Vincent / d’Orgeix, Emilie (eds.): Portefeuilles de plans: projets et dessins d'ingénieurs militaires en Europe du 16. au 19. siècle. Bourges: Conseil Général du Cher, pp. 147-158.

Viganò, Marino (2005): "Il Castello sforzesco, cittadella bastionata (XVI-XVIII) secolo”. En: Colmuto Zanella, Graziella / Iacobone, Damiano (eds.): Milano città fortificata, vent 'anni dopo. Milán: Comune Stampa, pp. 65-79.

Viganò, Marino (2007): “Josè Chafrion”. En: Bassi, Paolo, Langé, Santino, Repishti, Francesco (eds.): Ingegneri ducali e camerali nel ducato e nello stato di Milano (1450-1706). Dizionario Biobibliografico. Florencia: Edifir, 2007, pp. 61-62.

Warmoes, Isabelle / D’Orgeix, Emilie / Van den Heuvel, Charles (eds.) (2003): Atlas militaires manuscrits Européens (XVI-XVIII siècles). Forme, contenu, contexte de réalisation et vocations. París: Musée des Plans-Reliefs. 
Woodward, David (1997): “Italian Composite Atlases of the Sixteenth Century”. En: Wlater, Joan A., Grim, Ronald E. (eds.): Images of the World. The Atlas through History. Washington, DC: Library of Congress, pp. 51-70.

Woodward, David (2007a): “The Italian Map Trade, 1480-1560”. En: Woodward, David (ed.): Cartography in the European Renaissance. III vol. Chicago: University of Chicago Press, pp. 775-790.

Woodward, David (2007b): “Appendix”. En Woodward, David (ed.): Cartography in the European Renaissance. Vol. III. Chicago: University of Chicago Press, 2007, pp. 799-803.

Fecha de recepción: 9-IX-2019

Fecha de aceptación: 24-I-2020 